This is the peer reviewed version of the following article: Fu, Y. H.. et al. Larger temperature response of autumn leaf senescence than spring leaf-out-phenology in Global change biology (Ed. Wiley), vol. 24, issue 5 (May 2018), p. 2159-2168.

Which has been published in final form at DOI 10.1111/gcb.14021

This article may be used for non-commercial purposes in accordance with Wiley Terms and Conditions for Use of Self-Archived Versions. This version is published under a "All rights reserved" license. 


\section{Larger temperature response of autumn leaf senescence than spring leaf-out phenology}

3

4 Running title: temperature response of autumn leaf senescence

5 Antwerp, Universiteitsplein 1, B-2610 Wilrijk, Belgium University, Beijing 100871, China of Sciences, Beijing 100085, China 91400 Orsay, France 311300 Hangzhou, China out, temperature sensitivity

Paper type: Primary Research Articles Yongshuo H. Fu ${ }^{1,2 *}$, Shilong Piao ${ }^{3,4}$, Nicolas Delpierre ${ }^{5}$, Fanghua Hao ${ }^{1}$, Heikki Hänninen ${ }^{6}$, Yongjie Liu ${ }^{2}$, Wenchao Sun ${ }^{1}$, Ivan A. Janssens ${ }^{2}$, Matteo Campioli ${ }^{2}$

${ }^{1}$ College of water sciences, Beijing Normal University, Xinjiekouwaidajie 19, 100875, Beijing, China

${ }^{2}$ Centre of Excellence PLECO (Plant and Vegetation Ecology), Department of Biology, University of

${ }^{3}$ Sino-French Institute for Earth System Science, College of Urban and Environmental Sciences, Peking

${ }^{4}$ Institute of Tibetan Plateau Research, Center for Excellence in Tibetan Earth Science, Chinese Academy

${ }^{5}$ Ecologie Systématique Evolution, Univ. Paris-Sud, CNRS, Agro Paris Tech, Université Paris, Saclay,

${ }^{6}$ Zhejiang A\&F University, State Key Laboratory of Subtropical Silviculture, Huanbei Road No. 88,

Keywords: climate change, summer and autumn warming, leaf phenology, leaf senescence, leaf-

*Corresponding author: Yongshuo H. Fu, Tel: +32-651721, Email: $\underline{\text { Yongshuo.fu@uantwerpen.be }}$

Manuscript for Global Change Biology 


\section{Abstract}

30 Climate warming is substantially shifting the leaf phenological events of plants, and thereby

31 impacting on their individual fitness and also on the structure and functioning of ecosystems.

32 Previous studies have largely focused on the climate impact on spring phenology, and to date the

33 processes underlying leaf senescence and their associated environmental drivers remain poorly

34 understood. In this study, experiments with temperature gradients imposed during the summer

35 and autumn were conducted on saplings of European beech to explore the temperature responses

36 of leaf senescence. An additional warming experiment during winter enabled us to assess the

37 differences in temperature responses of spring leaf-out and leaf senescence. We found that

38 warming significantly delayed the dates of leaf senescence both during summer and autumn

39 warming, with similar temperature sensitivities (6 - 8 days delay per ${ }^{\circ} \mathrm{C}$ warming), suggesting

40 that, in the absence of water and nutrient limitation, temperature may be a dominant factor

41 controlling the leaf senescence in European beech. Interestingly, we found a significantly larger

42 temperature response of autumn leaf senescence than of spring leaf-out. This suggests a possible

43 larger contribution of delays in autumn senescence, than of the advancement in spring leaf-out,

44 to extending the growing season under future warmer conditions. 


\section{Introduction}

46 Plant phenology is the study of periodic plant life cycle events, and how these are influenced by

47 seasonal and interannual variations in climate (Lieth, 2013). Plant phenology is one of the most

48 reliable biological indicators of anthropogenic climate change (Parmesan \& Yohe, 2003, Root et

49 al., 2003, Walther et al., 2002), and changes in plant phenology impact on individual fitness,

50 species distribution, interspecific interactions, ecosystem structure and function, as well as on

51 feedbacks to the climate system (Chuine et al., 2010, Peñuelas \& Filella, 2009, Piao et al., 2007,

52 Thackeray et al., 2016, Zeng et al., 2017). Therefore, understanding the processes underlying

53 plant phenology is essential to improve our understanding of plant and ecosystem responses to

54 the ongoing climate change.

55

56 Plant phenology research has grown tremendously over the past four decades (Hänninen, 2016,

57 IPCC, 2014, Wolkovich \& Ettinger, 2014). Most studies, however, have addressed spring

58 phenological events, such as budburst, leaf-out and flowering (Fu et al., 2015, Richardson et al.,

59 2013), while autumn phenological events, such as leaf senescence, have been paid comparatively

60 less attention (Gallinat et al., 2015, Panchen et al., 2015). One probable reason for this is the

61 difficulty to accurately acquire leaf senescence observations in natural conditions. However, as

62 the final stage of the leaf's life cycle and as adaptive strategy to unfavorable environmental

63 conditions of temperate and boreal plant species (Chabot \& Hicks, 1982), leaf senescence is

64 critical to plants' fitness as well as to ecosystem functions (Estiarte \& Peñuelas, 2015, Piao et al.,

65 2008, Rohde \& Bhalerao, 2007).

66

67 The main function of autumn leaf senescence is to recycle nutrients from senescing leaves and transport them to other plant tissues to support growth during the following spring (Chapin III, 
1980, Killingbeck, 1996, Maillard et al., 2015). This nutrient-conservation mechanism increases

70 the fitness of individual plants, especially in nutrient poor environments (Chapin III, 1980, May

71 \& Killingbeck, 1992). Generally, more than half of the leaf macro-nutrients, such as $\mathrm{N}$ and P,

72 are being resorbed during the leaf senescence process, although the nutrient resorption efficiency

73 varies widely among species and elements (Aerts, 1996, Freschet et al., 2010, Wright \&

74 Westoby, 2003). Apart from its influence on nutrient cycles, the timing of leaf senescence

75 influences the ecosystem carbon balance by modulating the length of the photosynthetically

76 active period (Myneni et al., 1997, Richardson et al., 2010). Leaf senescence may even play a

77 more critical role than spring phenology in determining the length of the photosynthetically

78 active period (Garonna et al., 2014, Wu et al., 2013). Understanding the response of leaf

79 senescence to climate change is therefore important. However, to date, the processes underlying

80 autumn leaf senescence, their associated environmental controls and the response of leaf

81 senescence to climate change are still poorly understood.

82

83 Photoperiod has generally been proposed as the primary driver of leaf senescence, with a critical

84 photoperiodic threshold, i.e., a critical day length below which leaf senescence is triggered

85 (Lagercrantz, 2009, Wareing, 1956, Way \& Montgomery, 2015, Welling \& Palva, 2006). For

86 example, the autumnal senescence in mature European aspen occurs every year on almost the

87 same date (Fracheboud et al., 2009). However, photoperiod is not consistently important across

88 species and even sites. For example, a recent study reported that leaf senescence is not triggered

89 by photoperiod across 116 European aspen natural genotypes (Michelson et al., 2017),

90 suggesting that other environmental factors must be involved in driving the leaf senescence

91 process. In line with this finding, many studies have suggested that temperature interacts with 
92 photoperiod to control the leaf senescence process (Chung et al., 2013, Hänninen \& Tanino,

93 2011, Heide \& Prestrud, 2005, Liu et al., 2016a, Tanino et al., 2010), and that temperature can

94 be even the main controlling factor of leaf senescence (Chmielewski \& Rötzer, 2001, Estiarte \&

95 Peñuelas, 2015, Heide \& Prestrud, 2005, Xie et al., 2015), in particular autumn temperature

96 (Delpierre et al., 2009). However, these results are not conclusive because other studies have

97 shown that autumnal senescence is only weakly affected by air temperature (Čufar et al., 2012,

98 Olsson \& Jönsson, 2015, Sparks \& Menzel, 2002). In addition to photoperiod and temperature,

99 also other environmental factors have been reported to influence the leaf senescence process.

100 These include light intensity (Liu et al., 2016b), precipitation and soil water conditions (see

101 review in Estiarte and Peñuelas (2015)) and soil nutrient status (Sigurdsson, 2001, Weih, 2009).

102 Furthermore, a positive correlation was recently reported between spring leaf-out dates and

103 autumn leaf senescence dates, suggesting that the factors regulating the leaf-out days are carried

104 over to affect leaf senescence in the following autumn (Fu et al., 2014, Signarbieux et al., 2017).

105 Thus, the literature remains inconsistent about the determinants of autumn leaf senescence

106 (Estiarte \& Peñuelas, 2015), so that well-designed experiments are needed to investigate and

107 better understand the leaf senescence process.

108

109 Current studies of leaf senescence are generally based on either species-specific long-term in situ 110 observations (Menzel et al., 2006, Panchen et al., 2015), or on remote-sensing based

111 observations (Garonna et al., 2014, Julien \& Sobrino, 2009, Liu et al., 2016b, Shen et al., 2015,

112 Xie et al., 2015, Jeong et al.,2011). While manipulation experiments have been conducted, only

113 few have studied the autumn phase in relation to climate change, as opposed to spring

114 (Wolkovich et al., 2012). Furthermore, these few-experimental autumn phenology studies were 
115 designed with only one or two warming treatments (Gunderson et al., 2012, Marchin et al., 116 2015, Morin et al., 2010, Norby et al., 2003). How leaf senescence responds to a temperature

117 gradient, whether summer and autumn warming influence leaf senescence differently, and

118 whether autumn phenology has the same temperature sensitivity as spring phenology, to our

119 knowledge, has not yet been experimentally investigated.

120

121 In the present study, we therefore carried out gradient-warming/cooling manipulation

122 experiments using two-year old and one-meter-high saplings of Fagus sylvatica L. (European

123 beech), a widespread deciduous forest tree species in temperate Europe. Specifically, we exposed

124 the saplings to either summer or autumn warming. The primary objectives of this study were (1)

125 to quantify the temperature sensitivity of leaf senescence date (St, changes in days per ${ }^{\circ} \mathrm{C}$

126 warming); (2) to investigate the effect of summer versus autumn warming on leaf senescence

127 dates, and (3) to compare St of autumn senescence with that of spring leaf-out.

128

129 Materials and methods

130 Study site and climate chambers

131 The experiment was conducted in 12 climate-controlled transparent chambers at the Drie Eiken

132 campus of the University of Antwerp (Belgium, $51^{\circ} 19^{\prime} \mathrm{N}, 4^{\circ} 21^{\prime} \mathrm{E}$ ). The long-term mean annual

133 air temperature is $9.6^{\circ} \mathrm{C}$, and mean monthly air temperatures vary from $2.2^{\circ} \mathrm{C}$ in January to 17.0

$134{ }^{\circ} \mathrm{C}$ in July. Annual precipitation averages $780 \mathrm{~mm}$, being uniformly distributed throughout the

135 year (Campioli et al., 2012). The chambers could be artificially warmed/cooled by a centralized

136 heating/cooling system ensuring different levels of continuous (day and night) warming or

137 cooling above/below the fluctuating ambient air temperature (Fu et al., 2016). Each chamber 
could accommodate 12 saplings. Temperature sensors (Siemens, type QFA66, Berlin, Germany) were used to continuously monitor the air temperature inside each chamber, logging every 30 minutes and storing hourly data. Here, we combine the results from three different experiments performed in the climate chambers using beech saplings of the same provenance and size.

\section{Experimental design and leaf senescence measurements}

Tree material. The experiments used 2-year-old and one-meter-high saplings of Fagus sylvatica

L. grown from seeds of the same origin and cultivated in the same field for one year at a commercial nursery. We transplanted the saplings into plastic pots (diameter $25 \mathrm{~cm}$, depth 40 $\mathrm{cm})$. The pots were moved into the climate-controlled chambers during early summer, late summer or winter (see below). The pots were filled with a substrate that was created by combining potting soil and Lommel sand (grain size $<1 \mathrm{~mm}$ diameter), bought from commercial suppliers (Van den Broeck and Jos Meeussen \& Zoon bvba) in Belgium. In experiment 1 and 2, slow release fertilizer $\left(100 \mathrm{~g} \cdot \mathrm{m}^{-2}, 13-10-20\right.$ for $\mathrm{N}, \mathrm{P}$, and $\mathrm{K}$, respectively, all in percentage) was added in end of May to each sapling. Over the growing period, the saplings were watered at least three times per week to ensure no water limitation.

Experiment 1 (temperature treatment during summer, targeting leaf senescence) (Fig. 1). In this experiment, one control treatment $\left(+0^{\circ} \mathrm{C}\right)$ and three temperature treatments were applied: $+1^{\circ} \mathrm{C}$, $+3^{\circ} \mathrm{C}$ and $+4^{\circ} \mathrm{C}$. Two to four replicate chambers were used, except for the $+4^{\circ} \mathrm{C}$ treatment, for which data from only one chamber were available because one chamber failed. At summer solstice (21 June 2016), four saplings were placed in each chamber. The saplings were moved 
160 out at the "end of summer", i.e., on 15 August 2016. In total, 9 chambers and 36 saplings were 161 used in this experiment.

Experiment 2 (temperature treatment during autumn, targeting leaf senescence) (Fig. 1). In this experiment, we applied one control treatment $\left(+0^{\circ} \mathrm{C}\right)$, one cooling treatment $\left(-1^{\circ} \mathrm{C}\right)$ and one warming treatment $\left(+1^{\circ} \mathrm{C}\right)$, using three replicated chambers for each treatment. Four saplings were exposed to the treatment in each chamber during the autumn period, i.e. from 15 Aug 2016

167 to leaf senescence. In total, 9 chambers and 36 saplings were used in this experiment. 168

172 During the experiment, five warming temperature treatments, i.e. $+1^{\circ} \mathrm{C},+2^{\circ} \mathrm{C},+3{ }^{\circ} \mathrm{C},+4^{\circ} \mathrm{C}$ and $173+5^{\circ} \mathrm{C}$ (two chambers per treatment) and a control treatment $\left(+0^{\circ} \mathrm{C}\right)$ were applied. In total, 12 174 chambers and 48 saplings were used in this experiment.

176 The warming/cooling provided was generally stable for the experiments 1 and 3 (actual warming 177 was on average $\pm 10 \%$ of the prescribed value; see below for description of the experiments). 178 However, for experiment 2 (see below) the warming during autumn was less stable (within \pm $17920 \%$ ). This inaccuracy was not considered crucial, because our main analyses were based on the 180 actually realized warming/cooling (e.g. regression analysis, see below), not the envisaged 181 warming. 


\section{Observation of leaf senescence and leaf-out}

184 Leaf senescence was monitored following Vitasse et al. (2009). In detail, the number of leaves

185 with autumn colour was determined visually and the percentage of them, out of the total number

186 of leaves, was calculated. The senescence date was defined as the date when $50 \%$ of the leaves

187 had autumn colour. Leaf-out date was defined as the day when the entire leaf blade and the leaf

188 stalk were visible on the terminal buds (Fu et al., 2016).

189

190 Cooling degree hours

191 To evaluate the relationships between leaf senescence and air temperature, we calculated cooling

192 degree hours $(\mathrm{CDH})$ as the sum of hourly temperature below a temperature threshold ( $\left.\mathrm{T}_{\text {base }}\right)$

193 during the study period, i.e., from summer solstice (21 June) to the day of leaf senescence (LS)

194 (Dufrêne et al., 2005). The $\mathrm{T}_{\text {base }}$ was set at $25^{\circ} \mathrm{C}$, according to a previous study on Fagus

195 sylvatica (Delpierre et al., 2009):

$$
C D H=\sum_{\text {start }}^{L S}\left(\mathrm{~T}_{\text {base }}-\mathrm{T}_{\text {hourly })} \text { if } \mathrm{T}_{\text {hourly }}<\mathrm{T}_{\text {base }}\right.
$$

196 We also tested the use of a higher $\mathrm{T}_{\text {base, }}$ i.e. $30^{\circ} \mathrm{C}$, but found very similar results, and therefore 197 only reported the results based on $25^{\circ} \mathrm{C}$ in the main text.

\section{Data analysis}

199 The temperature responses of leaf senescence and leaf-out were evaluated using linear regression

200 based on the average dates obtained from the four saplings per chamber. The temperature

201 sensitivity of leaf senescence and leaf-out were defined as the slopes of the linear regression

202 between dates and the actual temperature change in the chambers. Independent samples $t$-tests

203 were used to evaluate the difference between leaf senescence, or leaf-out dates, as well as the 
accumulated $\mathrm{CDH}$, among different temperature treatments. Differences in the temperature sensitivity of leaf senescence between autumn cooling and autumn warming, and between summer and autumn, as well as in the temperature sensitivity between leaf senescence and leaf-

207 out, were tested using ANCOVA, i.e. testing the slopes and intercepts. All statistical analyses

208 were conducted using SPSS 16.0 (SPSS Inc., Chicago, IL, USA).

\section{Results}

\section{Leaf senescence response to experimental warming and cooling}

212 Leaf senescence dates were significantly delayed by the warming treatments, but were

213 significantly advanced by cooling (both $P<0.05$ ), as compared to the control treatment (Fig. 1a).

214 Although both summer and autumn warming significantly delayed the leaf senescence dates, 215 compared to the control, a larger delay (14 days on average) was found under summer warming 216 treatments than under autumn warming treatments (11 days on average) (Fig. 1a). As opposed to 217 the warming treatments, cooling significantly advanced the dates of leaf senescence, by 3 days 218 on average $(F=9.8 ; P=0.005$; Fig. $1 \mathrm{a})$.

\section{Temperature sensitivity of leaf senescence and leaf-out}

221 In the previous paragraphs the phenology responses were given, independent of the intensity of

222 the warming or cooling. This paragraph aims to render these treatments more comparable by

223 expressing all phenology changes on a per ${ }^{\circ} \mathrm{C}$ basis. By using a relative variable, we aim to

224 removing the influence of different periods (summer vs. autumn) and exposure times to warming.

225 On average, a rise of air temperature by one degree delayed the leaf senescence date by $6.4 \pm 1.1$

226 days, and the difference in the temperature sensitivity of leaf senescence (St, delay in days per ${ }^{\circ} \mathrm{C}$ 
227 warming) between autumn warming treatment (St_autumn, $8.3 \pm 1.1$ days $\left.{ }^{\circ} \mathrm{C}-1\right)$ and summer

228 warming treatment (St_summer, $6.1 \pm 0.8$ days $\left.{ }^{\circ} \mathrm{C}^{-1}\right)$ was not statistically significant $(P=0.75$,

229 Fig. 1b). The absolute St values of leaf senescence during autumn warming and autumn cooling

230 (-6.7 \pm 1.0 days ${ }^{\circ} \mathrm{C}^{-1}$ for cooling treatments) also did not differ statistically significantly (Fig. 2).

231

232 Warming significantly advanced the date of leaf-out in spring, with $4.5 \pm 0.5$ days advancement 233 per degree Celsius warming (Fig. 3a). Compared to the autumn leaf senescence (delay of $8.3 \pm$

2341.1 days ${ }^{\circ} \mathrm{C}^{-1}$ ), the temperature sensitivity of leaf-out was thus significantly lower (Fig. 3b), 235 suggesting a larger effect of climate warming on autumn leaf senescence than on spring leaf-out 236 phenology.

237

238 Correlation between leaf senescence and cooling degree hours

239 No significant correlation was found between leaf senescence dates and CDH that were 240 accumulated from 21 June to the day of leaf senescence across the temperature treatments $241\left(R^{2}=0.09, P=0.12\right.$, Fig. 4). In addition, the $\mathrm{CDH}$ requirement was not significantly different 242 between the two autumn treatments, i.e., $14677 \mathrm{~K}$ and $13067 \mathrm{~K}$ for autumn warming treatment 243 and autumn cooling treatment, respectively. However, the $\mathrm{CDH}$ requirement of saplings in the 244 summer warming treatment was statistically significantly lower than in the autumn warming and 245 autumn cooling treatments $(P<0.05)$.

247 Discussion

248 Previous studies have highlighted the ambiguous nature of the warming response of leaf 249 senescence (Gunderson et al., 2012, Heide \& Prestrud, 2005, Menzel et al., 2006), and 
250 attributed this to the limited availability of long-term datasets, the difficulty of quantifying the

251 exact date of leaf senescence under natural conditions, and the lack of focused experimental

252 studies designed to understand the leaf senescence response to temperature. For temperate trees

253 under favorable conditions, i.e., without water or nutrient stress, it is generally assumed that the

254 leaf senescence process is mainly triggered by photoperiod and temperature (Lieth, 2013, Way \&

255 Montgomery, 2015). Some studies reported a delayed trend of leaf senescence with climate

256 warming, based on in situ observations (Delpierre et al., 2009, Vitasse et al., 2011), remote

257 sensing observations (Liu et al., 2016b, Reed et al., 2009, Stöckli \& Vidale, 2004), as well as

258 open top chamber-based field warming experiments (Gunderson et al., 2012). In contrast, other

259 studies reported insignificant responses or even advanced senescence with climate warming

260 (Norby et al., 2003, Xie et al., 2015), which may be related to warming-induced drought stress

261 (Xie et al., 2015). Based on gradient warming experiments, in which drought was excluded, our

262 study clearly revealed that warming significantly delays the timing of leaf senescence in

263 European beech saplings in both summer and autumn warming, with even more than 30 days

264 delay under the $+4^{\circ} \mathrm{C}$ treatment $\left(4^{\circ} \mathrm{C}\right.$ higher than ambient). This suggested that, under sufficient

265 water and nutrient conditions, temperature may be more important than photoperiod in

266 controlling the leaf senescence process under temperate latitudes. In fact, if there was a

267 photoperiod threshold, this would have been overpassed by up to 30 days. Note that we found a

268 larger delay (14 days on average) under summer warming treatments than under autumn

269 warming treatments, this was, however, maybe largely attributed to the more intensive warming

270 treatment that was applied during summer (warmed up to ca. $4^{\circ} \mathrm{C}$ ) than during autumn (warmed

271 up to ca. $1^{\circ} \mathrm{C}$ ) (see Fig. 1b). We also did not find a statistical difference of the temperature

272 sensitivity of leaf senescence between autumn warming and autumn cooling treatments. This 
273 may be due to the limited sample size in this study, i.e. only one cooling treatment and one

274 warming treatment during autumn, and therefore this conclusion needs to be further studied. In

275 addition, we found a larger temperature sensitivity of leaf senescence, with 6-8 days delay per

276 degree Celsius warming, as opposed to 2-7 days delay per ${ }^{\circ} \mathrm{C}$ warming found in earlier

277 experimental studies (Gunderson et al., 2012, Han et al., 2014, Nakamura et al., 2010). This

278 difference might be related to species differences, to differences in the local environment, as well

279 as to the different experimental designs, i.e., only one or two warming treatments in the previous

280 studies versus gradient warming/cooling in the present study.

281

282 Surprisingly, there were no statistically significant differences in the sensitivity of the leaf

283 senescence process to summer and autumn warming. This implies that the positive impacts of

284 warming on leaf physiology, such as delayed chlorophyll degradation (Fracheboud et al., 2009),

285 leading to delayed leaf senescence at the end of the growing period, does not depend on the

286 seasonal timing of the temperature elevation. Nonetheless, warming may affect different

287 processes during summer (e.g. predominantly cell division and expansion) than during autumn

288 (cell maturation and lignification). Furthermore, warming might affect different phases of the

289 leaf senescence process when applied in summer versus autumn. During summer, warming

290 might delay the leaf senescence onset, whereas autumn warming might slow down the

291 progression rate of the leaf senescence (Fracheboud et al., 2009). These different aspects (delay

292 in leaf senescence onset vs. slowdown of leaf senescence rate) cannot be independently assessed

293 with the coloration method we used. 
295 The lower CDH requirement associated with the summer treatment should be related to more

296 intense warming in summer than in autumn. We do not believe that the low CDH requirement in

297 summer is related to differences in the leaf senescence date as summer warming elicited, on

298 average, later leaf senescence than autumn warming, which should have caused a larger CDH.

299 The timing of leaf senescence simulated by cooling degree days-based models has been

300 compared in earlier studies with in situ observations (Archetti et al., 2013, Delpierre et al., 2009,

301 Jolly et al., 2005, Vitasse et al., 2011). Consistent with the assumption of degree days-based

302 models, we found that the differences in the cooling degree hours (CDH) required for leaf

303 senescence between the two autumn treatments were statistically insignificant. Furthermore,

304 good model performances were found in boreal tree species (Koski \& Selkäinaho, 1985,

305 Partanen, 2004, Viherä-Aarnio et al., 2005). However, contrary to the results of the present study,

306 these studies found that warming during summer and autumn would advance, not delay, the

307 timing of leaf senescence. Possibly, this opposite temperature response is attributable to

308 differences among boreal and temperate-zone species. Jeong and Medvigy (2014) reported a

309 nonlinear temperature sensitivity of leaf senescence using many ground observations and

310 suggested that warmer regions may have a larger temperature sensitivity than cooler regions. In

311 addition, recent studies have reported a positive correlation between spring leaf-out and leaf

312 senescence dates in trees ( $\mathrm{Fu}$ et al., 2014, Signarbieux et al., 2017), delayed senescence

313 following exceptionally late spring greening in sub-arctic grasslands (Leblans et al., 2017), and

314 the performance of senescence models was substantially improved by incorporating this legacy 315 effect. 
317 Interestingly, we found a larger temperature sensitivity (St) of autumn leaf senescence than 318 spring leaf-out using European beech saplings of the same age. Contrasting conclusions were 319 obtained from a meta-analysis of observations on mature trees from the European phenology 320 network, which reported a larger St of spring leaf-out $\left(4.6 \pm 0.07\right.$ days $\left.{ }^{\circ} \mathrm{C}^{-1}\right)$ than of autumn leaf 321 colouring $\left(1.0 \pm 0.4\right.$ days $\left.{ }^{\circ} \mathrm{C}^{-1}\right)$ across plant species (Menzel et al., 2006). This difference may be 322 attributable to the species-specific differences in the phenology response to temperature 323 (Panchen et al., 2015, Richardson et al., 2006, Vitasse et al., 2009). However, similar finding 324 was reported on Quercus variabilis seedlings in an open-field warming experiment (Han et al., 325 2014), and on mature beech trees in an altitude gradient (Vitasse et al., 2009). The difference in 326 temperature sensitivity of leaf-out and leaf senescence are likely related to the differential 327 processes between spring and autumn phenology. Concerning spring leaf-out (particularly for 328 diffuse porous species like beech), temperature impacts the end of bud dormancy and the speed 329 of leaf unfolding but no other trees organ (which are inactive before budburst) (Delpierre et al., 330 2016). On the other hand, in autumn, temperature impacts both the leaf physiological status 331 (chlorophyll content, photosynthesis, pigment degradation etc) and tree growth (e.g. wood 332 lignification, fine root growth). The latter reduction of carbon sink activity at the tree scale may 333 be an additional, overlooked trigger of leaf senescence. These interactions might affect leaf 334 senescence onset, in other words not only leaf status but also (and maybe primarily) a lack of 335 sink activity might trigger leaf senescence (see hypothesis in Fu et al., 2014). Therefore, it is 336 logical that temperature has a strong effect on autumn phenology, which, as showed by our data, 337 and even can be stronger than that on spring phenology. 
339 Given the larger warming response of leaf senescence than of spring leaf-out found in the present

340 study, under future climate warming conditions we can expect a larger contribution of the delay

341 in autumn senescence dates to the extension of photosynthetic season than of the earlier spring

342 leaf-out. Thus, warming induced changes in leaf senescence could play an important role in the

343 ecosystem carbon balance (Keenan et al., 2014, Piao et al., 2008). However, delayed leaf

344 senescence in response to warmer summers-autumns may increase the risk of extreme events

345 such early-frost damage to leaves (Augspurger, 2013, Hänninen, 2016, Inouye, 2008), which

346 would hamper the nutrient resorption. This can lead to reduced nutrient reserves to support next

347 season's growth, and subsequentially impact the ecosystem carbon and nutrient cycles (Estiarte

$348 \&$ Peñuelas, 2015, Fracheboud et al., 2009). Finally, note that considering the legacy effect of

349 leaf-out on the leaf senescence dates ( $\mathrm{Fu}$ et al., 2014), the delays in leaf senescence as observed

350 in our experiments might be partially offset by the earlier spring leaf-out in response to warmer

351 winters.

352

353 The underlying physiological processes of leaf senescence and their environmental cues,

354 especially the interactive effect of temperature and photoperiod, are still unclear. Moreover,

355 warming responses of leaf senescence largely differ between natural observations and warming

356 experiments (Wolkovich et al., 2012), ontogenetic differences have been reported between

357 saplings and mature trees (Mediavilla et al., 2014, Vitasse, 2013), and species variability exists

358 in response to warming (Parmesan \& Hanley, 2015, Primack et al., 2015). Nonetheless, our

359 study provides important insights. Taking advantage of temperature manipulative experiments,

360 we found that, in the absence of water and nutrient limitation, temperature is a dominant factor

361 controlling the leaf senescence process in European beech, and warming during summer and 
362 autumn both significantly delay the date of leaf senescence. Furthermore, we found a larger

363 temperature response of leaf senescence than spring leaf-out. These findings enhance our

364 understanding of leaf phenology response to the climate change, and potentially improve our

365 understanding of phenological impacts on ecosystem carbon and nutrient cycles.

366

367 Acknowledgments

368 This study is supported by the General program of National Nature science foundation of China

369 (No. 31770516), the National Key Research and Development Program of China

370 (2017YFA06036001) and the Thousands Talents Program for Young Professionals. Matteo

371 Campioli is a Postdoctoral Fellow of the Research Foundation-Flanders (FWO) and

372 acknowledges ERC for support through ERC-2016-StG-714916 “LEAF-FALL”. Ivan A

373 Janssens acknowledges support from the European Research Council (ERC) through Synergy

374 grant ERC-2013-SyG-610028 "P-IMBALANCE” and support from the University Of Antwerp.

375 


\section{Reference}

Aerts R (1996) Nutrient resorption from senescing leaves of perennials: are there general patterns? Journal of Ecology, 597-608.

Archetti M, Richardson AD, O'keefe J, Delpierre N (2013) Predicting climate change impacts on the amount and duration of autumn colors in a New England forest. PLoS One, 8, e57373.

Augspurger CK (2013) Reconstructing patterns of temperature, phenology, and frost damage over 124 years: spring damage risk is increasing. Ecology, 94, 41-50.

Campioli M, Vincke C, Jonard M, Kint V, Demarée G, Ponette Q (2012) Current status and predicted impact of climate change on forest production and biogeochemistry in the temperate oceanic European zone: review and prospects for Belgium as a case study. Journal of forest research, 17, 1-18.

Chabot BF, Hicks DJ (1982) The ecology of leaf life spans. Annual review of ecology and systematics, 13, 229-259.

Chapin Iii FS (1980) The mineral nutrition of wild plants. Annual review of ecology and systematics, 11, 233-260.

Chmielewski F-M, Rötzer T (2001) Response of tree phenology to climate change across Europe. Agricultural and Forest Meteorology, 108, 101-112.

Chuine I, Morin X, Bugmann H (2010) Warming, Photoperiods, and Tree Phenology. Science, 329, 277-278.

Chung H, Muraoka H, Nakamura M, Han S, Muller O, Son Y (2013) Experimental warming studies on tree species and forest ecosystems: a literature review. Journal of plant research, 126, 447-460.

Čufar K, De Luis M, Saz MA, Črepinšek Z, Kajfež-Bogataj L (2012) Temporal shifts in leaf phenology of beech (Fagus sylvatica) depend on elevation. Trees, 26, 1091-1100.

Delpierre N, Dufrêne E, Soudani K, Ulrich E, Cecchini S, Boé J, François C (2009) Modelling interannual and spatial variability of leaf senescence for three deciduous tree species in France. Agricultural and Forest Meteorology, 149, 938-948.

Delpierre, N., Vitasse, Y., Chuine, I., Guillemot, J., Bazot, S., \& Rathgeber, C. B. (2016). Temperate and boreal forest tree phenology: from organ-scale processes to terrestrial ecosystem models. Annals of Forest Science, 73(1), 5-25.

Dufrêne E, Davi H, François C, Le Maire G, Le Dantec V, Granier A (2005) Modelling carbon and water cycles in a beech forest: Part I: Model description and uncertainty analysis on modelled NEE. Ecological Modelling, 185, 407-436.

Estiarte M, Peñuelas J (2015) Alteration of the phenology of leaf senescence and fall in winter deciduous species by climate change: effects on nutrient proficiency. Global Change Biology, 21, 1005-1017.

Fracheboud Y, Luquez V, Björkén L, Sjödin A, Tuominen H, Jansson S (2009) The control of autumn senescence in European aspen. Plant Physiology, 149, 1982-1991. 
Freschet GT, Cornelissen JH, Van Logtestijn RS, Aerts R (2010) Substantial nutrient resorption from leaves, stems and roots in a subarctic flora: what is the link with other resource economics traits? New Phytologist, 186, 879-889.

Fu YH, Campioli M, Vitasse Y et al. (2014) Variation in leaf flushing date influences autumnal senescence and next year's flushing date in two temperate tree species. Proceedings of the National Academy of Sciences, 111, 7355-7360.

Fu YH, Liu Y, De Boeck HJ et al. (2016) Three times greater weight of daytime than of nighttime temperature on leaf unfolding phenology in temperate trees. New Phytologist, 212, 590-597.

Fu YH, Zhao HF, Piao SL et al. (2015) Declining global warming effects on the phenology of spring leaf unfolding. Nature, 526, 104-+.

Gallinat AS, Primack RB, Wagner DL (2015) Autumn, the neglected season in climate change research. Trends in ecology \& evolution, 30, 169-176.

Garonna I, Jong R, Wit AJ, Mücher CA, Schmid B, Schaepman ME (2014) Strong contribution of autumn phenology to changes in satellite- derived growing season length estimates across Europe (1982-2011). Global Change Biology, 20, 3457-3470.

Gunderson CA, Edwards NT, Walker AV, O'hara KH, Campion CM, Hanson PJ (2012) Forest phenology and a warmer climate-growing season extension in relation to climatic provenance. Global Change Biology, 18, 2008-2025.

Han S, Chung H, Noh NJ et al. (2014) Effect of open-field experimental warming on the leaf phenology of oriental oak (Quercus variabilis) seedlings. Journal of Plant Ecology, 7, 559-566.

Hänninen H (2016) Boreal and temperate trees in a changing climate. Springer Science Business Media, Dordrect.

Hänninen H, Tanino K (2011) Tree seasonality in a warming climate. Trends in Plant Science, 16, 412-416.

Heide O, Prestrud A (2005) Low temperature, but not photoperiod, controls growth cessation and dormancy induction and release in apple and pear. Tree physiology, 25, 109-114.

Inouye DW (2008) Effects of climate change on phenology, frost damage, and floral abundance of montane wildflowers. Ecology, 89, 353-362.

Ipcc (2014) Climate change 2013: the physical science basis: Working Group I contribution to the Fifth assessment report of the Intergovernmental Panel on Climate Change, Cambridge University Press.

Jeong, S. J., HO, C. H., GIM, H. J., \& Brown, M. E. (2011). Phenology shifts at start vs. end of growing season in temperate vegetation over the Northern Hemisphere for the period 1982-2008. Global Change Biology, 17(7), 2385-2399.

Jeong, S. J., \& Medvigy, D. (2014) Macroscale prediction of autumn leaf coloration throughout the continental United States. Global ecology and biogeography, 23(11), 1245-1254.

Jolly WM, Nemani R, Running SW (2005) A generalized, bioclimatic index to predict foliar phenology in response to climate. Global Change Biology, 11, 619-632. 
Julien Y, Sobrino J (2009) Global land surface phenology trends from GIMMS database. International Journal of Remote Sensing, 30, 3495-3513.

Keenan TF, Gray J, Friedl MA et al. (2014) Net carbon uptake has increased through warminginduced changes in temperate forest phenology. Nature Climate Change, 4, 598.

Killingbeck KT (1996) Nutrients in senesced leaves: keys to the search for potential resorption and resorption proficiency. Ecology, 77, 1716-1727.

Koski V, Sievänen R (1985) Timing of growth cessation in relation to the variations in the growing season. In: Tigerstedt PMA, Puttonen P, Koski V (Eds) Crop physiology of forest trees. Helsinki University Press. Helsinki, Finland. p. 167-193.

Lagercrantz U (2009) At the end of the day: a common molecular mechanism for photoperiod responses in plants? Journal of experimental botany, 60, 2501-2515.

Leblans N, Sigurdsson B, Vicca S, Fu Y, Penuelas J, Janssens I (2017) Phenological responses of Icelandic subarctic grasslands to short- term and long- term natural soil warming. Global Change Biology.

Lieth, H. (1974). Purposes of a phenology book. In Phenology and seasonality modeling (pp. 319). Springer Berlin Heidelberg.

Liu Q, Fu YH, Zeng Z, Huang M, Li X, Piao S (2016a) Temperature, precipitation, and insolation effects on autumn vegetation phenology in temperate China. Global Change Biology, 22, 644-655.

Liu Q, Fu YH, Zhu Z et al. (2016b) Delayed autumn phenology in the Northern Hemisphere is related to change in both climate and spring phenology. Global Change Biology, 22, 3702-3711.

Maillard A, Diquélou S, Billard V et al. (2015) Leaf mineral nutrient remobilization during leaf senescence and modulation by nutrient deficiency. Frontiers in plant science, $\mathbf{6}$.

Marchin RM, Salk CF, Hoffmann WA, Dunn RR (2015) Temperature alone does not explain phenological variation of diverse temperate plants under experimental warming. Global Change Biology, 21, 3138-3151.

May JD, Killingbeck KT (1992) Effects of preventing nutrient resorption on plant fitness and foliar nutrient dynamics. Ecology, 73, 1868-1878.

Mediavilla S, Herranz M, González-Zurdo P, Escudero A (2014) Ontogenetic transition in leaf traits: a new cost associated with the increase in leaf longevity. Journal of Plant Ecology, 7, 567-575.

Menzel A, Sparks TH, Estrella N et al. (2006) European phenological response to climate change matches the warming pattern. Global Change Biology, 12, 1969-1976.

Michelson IH, Ingvarsson PK, Robinson KM, Edlund E, Eriksson ME, Nilsson O, Jansson S (2017) Autumn senescence in aspen is not triggered by day length. Physiologia Plantarum.

Morin X, Roy J, Sonié L, Chuine I (2010) Changes in leaf phenology of three European oak species in response to experimental climate change. New Phytologist, 186, 900-910. 
Myneni RB, Keeling C, Tucker CJ, Asrar G, Nemani RR (1997) Increased plant growth in the northern high latitudes from 1981 to 1991. Nature, 386, 698.

Nakamura M, Muller O, Tayanagi S, Nakaji T, Hiura T (2010) Experimental branch warming alters tall tree leaf phenology and acorn production. Agricultural and Forest Meteorology, 150, 1026-1029.

Norby RJ, Hartz- Rubin JS, Verbrugge MJ (2003) Phenological responses in maple to experimental atmospheric warming and $\mathrm{CO} 2$ enrichment. Global Change Biology, 9, 1792-1801.

Olsson C, Jönsson AM (2015) A model framework for tree leaf colouring in Europe. Ecological Modelling, 316, 41-51.

Panchen ZA, Primack RB, Gallinat AS, Nordt B, Stevens A-D, Du Y, Fahey R (2015) Substantial variation in leaf senescence times among 1360 temperate woody plant species: implications for phenology and ecosystem processes. Annals of botany, 116, 865-873.

Parmesan C, Hanley ME (2015) Plants and climate change: complexities and surprises. Annals of botany, 116, 849-864.

Parmesan C, Yohe G (2003) A globally coherent fingerprint of climate change impacts across natural systems. Nature, 421, 37.

Partanen J (2004) Dependence of photoperiodic response of growth cessation on the stage of development in Picea abies and Betula pendula seedlings. Forest Ecology and Management, 188, 137-148.

Peñuelas J, Filella I (2009) Phenology feedbacks on climate change. Science, 324, 887-888.

Piao S, Ciais P, Friedlingstein P et al. (2008) Net carbon dioxide losses of northern ecosystems in response to autumn warming. Nature, $\mathbf{4 5 1}, 49$.

Piao S, Friedlingstein P, Ciais P, Viovy N, Demarty J (2007) Growing season extension and its impact on terrestrial carbon cycle in the Northern Hemisphere over the past 2 decades. Global Biogeochemical Cycles, 21.

Primack RB, Laube J, Gallinat AS, Menzel A (2015) From observations to experiments in phenology research: investigating climate change impacts on trees and shrubs using dormant twigs. Annals of botany, 116, 889-897.

Reed BC, Schwartz MD, Xiao X (2009) Remote sensing phenology. In: Phenology of ecosystem processes. pp Page., Springer.

Richardson AD, Bailey AS, Denny EG, Martin CW, O'keefe J (2006) Phenology of a northern hardwood forest canopy. Global Change Biology, 12, 1174-1188.

Richardson AD, Black TA, Ciais P et al. (2010) Influence of spring and autumn phenological transitions on forest ecosystem productivity. Philosophical Transactions of the Royal Society of London B: Biological Sciences, 365, 3227-3246.

Richardson AD, Keenan TF, Migliavacca M, Ryu Y, Sonnentag O, Toomey M (2013) Climate change, phenology, and phenological control of vegetation feedbacks to the climate system. Agricultural and Forest Meteorology, 169, 156-173. 
Rohde A, Bhalerao RP (2007) Plant dormancy in the perennial context. Trends in plant science, 12, 217-223.

Root TL, Price JT, Hall KR, Schneider SH (2003) Fingerprints of global warming on wild animals and plants. Nature, 421, 57.

Shen M, Piao S, Cong N, Zhang G, Jassens IA (2015) Precipitation impacts on vegetation spring phenology on the Tibetan Plateau. Global Change Biology, 21, 3647-3656.

Signarbieux C, Toledano E, Sanginés De Carcer P, Fu YH, Schlaepfer R, Buttler A, Vitasse Y (2017) Asymmetric effects of cooler and warmer winters on beech phenology last beyond spring. Global Change Biology.

Sigurdsson BD (2001) Elevated [CO 2] and nutrient status modified leaf phenology and growth rhythm of young Populus trichocarpa trees in a 3-year field study. Trees-Structure and Function, 15, 403-413.

Sparks TH, Menzel A (2002) Observed changes in seasons: an overview. International Journal of Climatology, 22, 1715-1725.

Stöckli R, Vidale PL (2004) European plant phenology and climate as seen in a 20-year AVHRR land-surface parameter dataset. International Journal of Remote Sensing, 25, 3303-3330.

Tanino KK, Kalcsits L, Silim S, Kendall E, Gray GR (2010) Temperature-driven plasticity in growth cessation and dormancy development in deciduous woody plants: a working hypothesis suggesting how molecular and cellular function is affected by temperature during dormancy induction. Plant molecular biology, 73, 49-65.

Thackeray SJ, Henrys PA, Hemming D et al. (2016) Phenological sensitivity to climate across taxa and trophic levels. Nature.

Viherä-Aarnio A, Häkkinen R, Partanen J, Luomajoki A, Koski V (2005) Effects of seed origin and sowing time on timing of height growth cessation of Betula pendula seedlings. Tree physiology, 25, 101-108.

Vitasse Y (2013) Ontogenic changes rather than difference in temperature cause understory trees to leaf out earlier. New Phytologist, 198, 149-155.

Vitasse Y, François C, Delpierre N, Dufrêne E, Kremer A, Chuine I, Delzon S (2011) Assessing the effects of climate change on the phenology of European temperate trees. Agricultural and Forest Meteorology, 151, 969-980.

Vitasse Y, Porté AJ, Kremer A, Michalet R, Delzon S (2009) Responses of canopy duration to temperature changes in four temperate tree species: relative contributions of spring and autumn leaf phenology. Oecologia, 161, 187-198.

Walther G-R, Post E, Convey P et al. (2002) Ecological responses to recent climate change. Nature, 416, 389-395.

Wareing P (1956) Photoperiodism in woody plants. Annual Review of Plant Physiology, 7, 191214.

Way DA, Montgomery RA (2015) Photoperiod constraints on tree phenology, performance and migration in a warming world. Plant, Cell \& Environment, 38, 1725-1736. 
571 Weih M (2009) Genetic and environmental variation in spring and autumn phenology of biomass 572 willows (Salix spp.): effects on shoot growth and nitrogen economy. Tree physiology, 29, 573 1479-1490.

574 Welling A, Palva ET (2006) Molecular control of cold acclimation in trees. Physiologia

575 Plantarum, 127, 167-181.

576 Wolkovich EM, Cook BI, Allen JM et al. (2012) Warming experiments underpredict plant

577 phenological responses to climate change. Nature, 485, 494.

578 Wolkovich EM, Ettinger AK (2014) Back to the future for plant phenology research. New 579 Phytologist, 203, 1021-1024.

580 Wright IJ, Westoby M (2003) Nutrient concentration, resorption and lifespan: leaf traits of 581 Australian sclerophyll species. Functional Ecology, 17, 10-19.

582 Wu C, Chen JM, Black TA et al. (2013) Interannual variability of net ecosystem productivity in 583 forests is explained by carbon flux phenology in autumn. Global Ecology and Biogeography, 22, 994-1006.

Xie Y, Wang X, Silander JA (2015) Deciduous forest responses to temperature, precipitation, and drought imply complex climate change impacts. Proceedings of the National Academy of Sciences, 112, 13585-13590.

590

Zeng Z, Piao S, Li LZ et al. (2017) Climate mitigation from vegetation biophysical feedbacks during the past three decades. Nature Climate Change, 7, 432-436. 
$591 \quad$ Figure captions

592

593 Fig 1. (a) The distribution, mean, and standard deviation (plot box) of the leaf senescence dates 594 of European beech saplings under different temperature manipulations and the control. Each grey 595 dot indicates the result for one sapling. (b) Relationship between leaf senescence dates of 596 European beech saplings and the mean temperature change in the treatments, as compared with 597 the ambient temperature. Open circles: Experiment 1, i.e. temperature treatment over the summer 598 period (from summer solstice to 15 August 2016); Grey squares: Experiment 2, temperature 599 treatment over the autumn period (from 15 August 2016 to the date of leaf senescence). The grey 600 line and shaded areas represent linear regression fits (with 95\% confidence intervals) across 601 summer and autumn treatments.

602

603 Fig 2. Temperature sensitivities of leaf senescence to autumn (from 15 August 2016 to the date 604 of leaf senescence) cooling and warming. The temperature sensitivity was calculated using 605 simple linear regression. The difference in the sensitivity between autumn cooling and warming 606 is not statistically significant 607

608 Fig 3. (a) Experiment 3: temperature treatment during winter-spring 2016. The temperature 609 sensitivity of leaf-out, in relation to the mean temperature change in the treatments, as compared 610 with the ambient temperature. (b) A comparison of the temperature sensitivity of leaf-out and 611 leaf senescence. The asterisk indicates a statistically significant difference $(P<0.05)$.

612

613 Fig 4. Correlation between leaf senescence dates and cooling degree hours accumulated in the 614 different treatments. Each dot denotes one climate-controlled chamber. The color bar shows the 
615 temperature anomalies in the temperature treatments (blue is control). Treatment of summer

616 warming (squares) refers to the period from summer solstice to 15 August 2016; autumn

617 warming (circles) and autumn cooling (diamonds) refer to the period from 15 August 2016 to the 618 date of leaf senescence.

619 
621
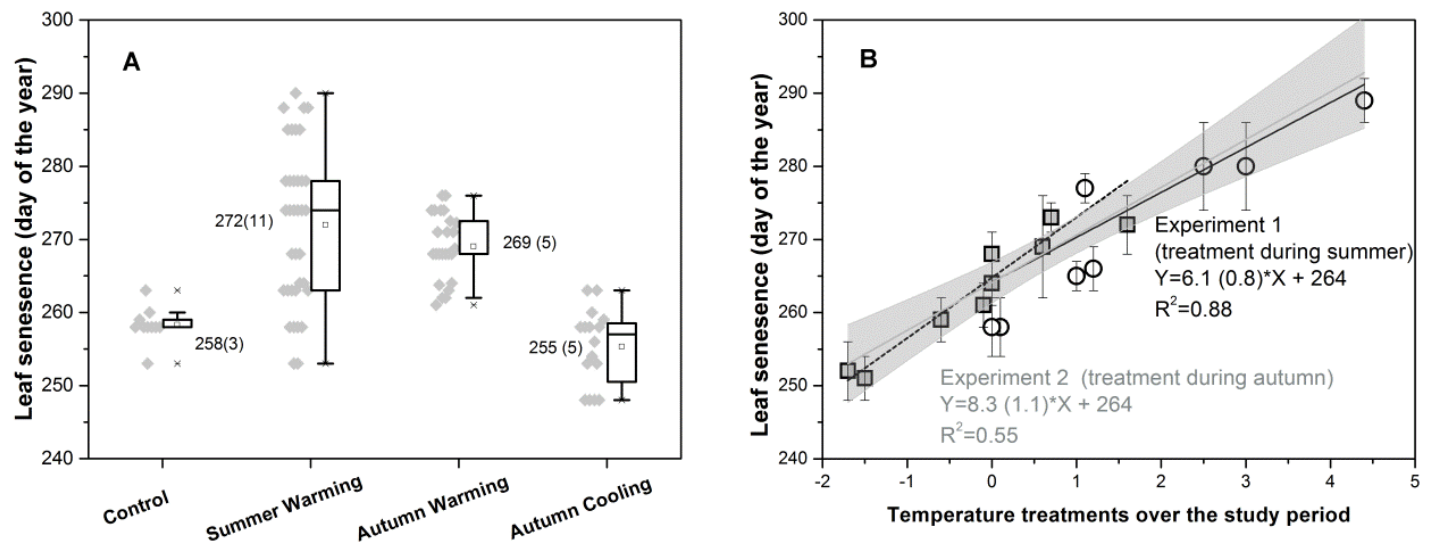

623

624 
625 FIGURE 2

626

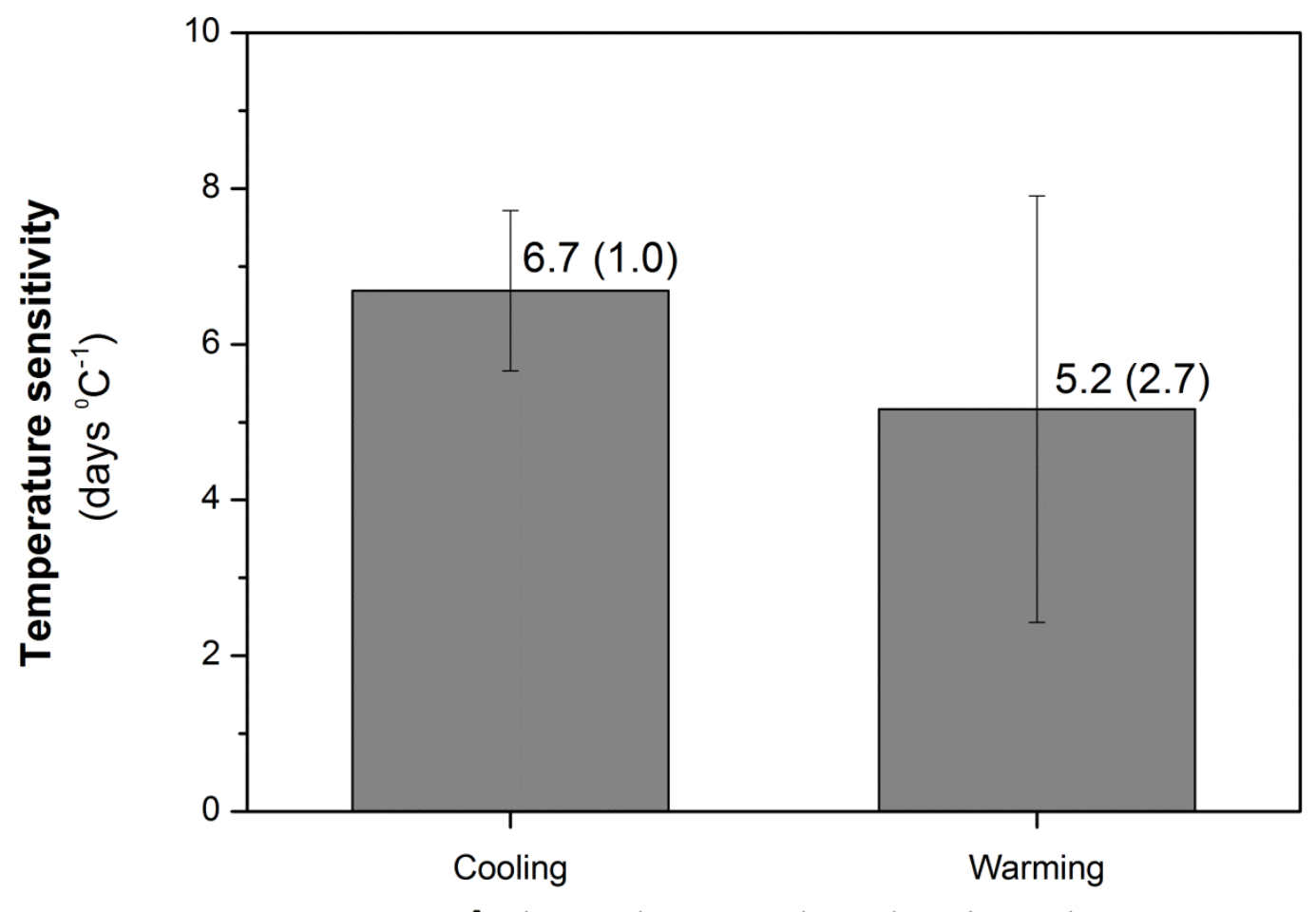

Autumn temperature treatment

627

628 
630
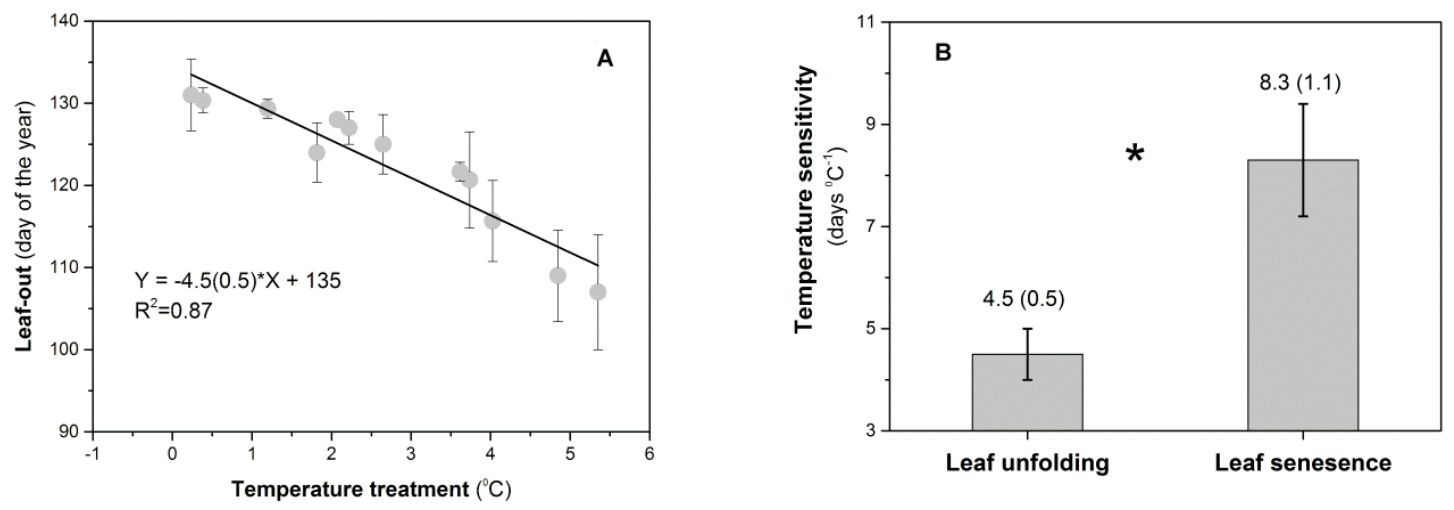

631

632

633 
635

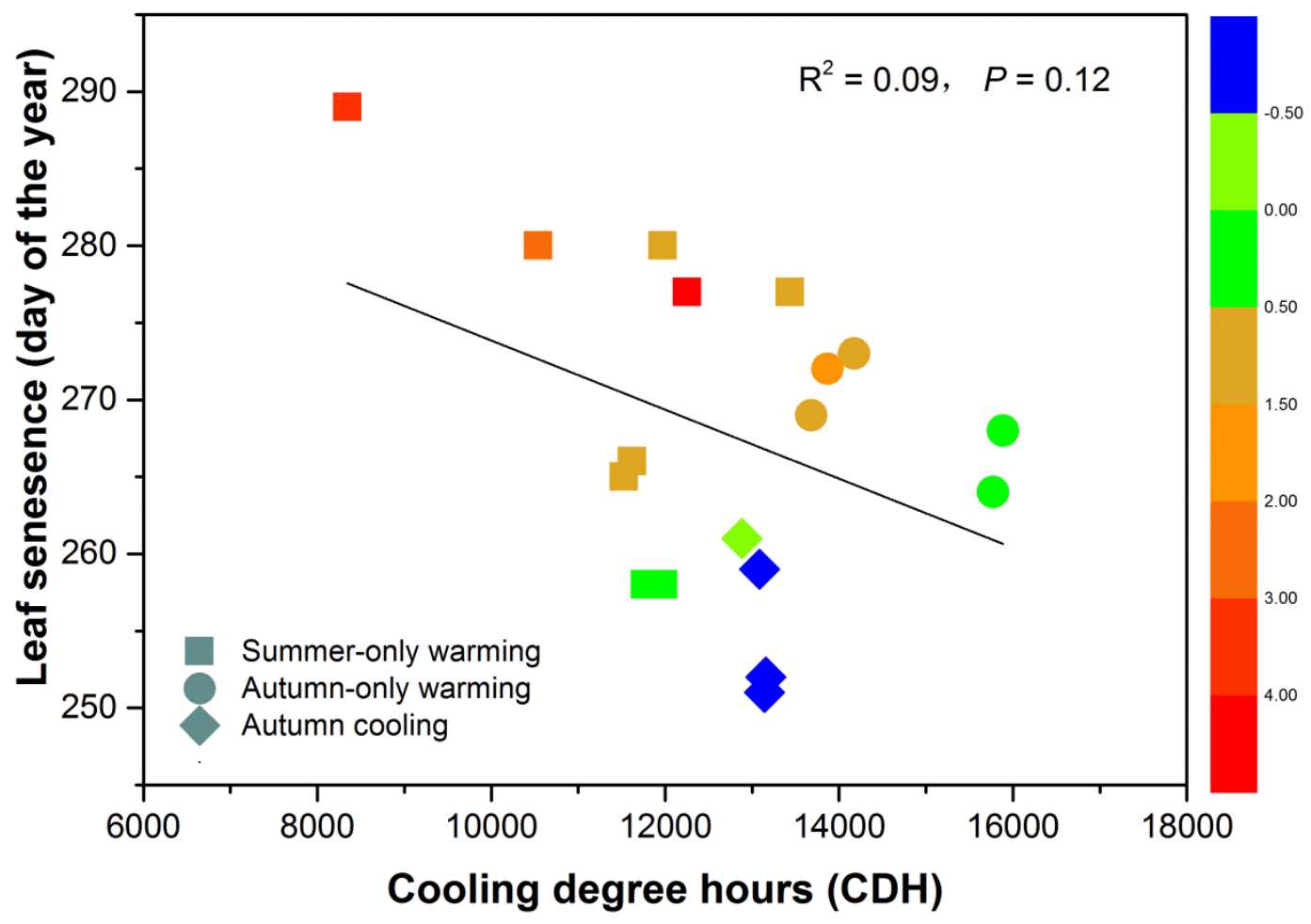

636 